\title{
Innovation and operation with robotized underwater systems
}

\author{
Vincent Rigaud \\ Director of the underwater system Dept Ifremer \\ Zone portuaire de Brégaillon 83507 \\ La Seyne sur Mer France \\ vincent.rigaud@ifremer.fr
}

\begin{abstract}
:
This paper reports on the status and design of the operational remotely operated vehicle Victor 6000 , rated for $6000 \mathrm{~m}$ depth and of the $3000 \mathrm{~m}$ depth autonomous underwater vehicle Asterxx operated by Ifremer the French Institute for Sea Exploitation. Victor 6000 is part of a global system built of subsystems, scientific modules, winch and cable, dead weight and umbilical, positioning subsystem using acoustic ultra short base line (USBL) techniques, and software for data and dive management. In 2005 the system was equipped with a second toolsled dedicated to high resolution mapping of the sea bed, with both acoustical and optical devices. Asterxx, the first autonomous underwater vehicle (AUV) developed by IFREMER, is $4.5 \mathrm{~m}$ in length with a diameter of $0.69 \mathrm{~m}$. Depending on the payload, its weight is between 600 and $800 \mathrm{~kg}$ in air,with a diving depth of $3000 \mathrm{~m}$. Its cruising speed is between 0.5 and $2.5 \mathrm{~ms}$. The AUV is capable of carrying various payloads for a wide spectrum of applications. The vehicle can cruise up to $100 \mathrm{~km}$. For coastal applications this vehicle is operable by a limited crew potentially from a nonspecialized vessel. Both vehicles are used for oceanography as well as to continually evolve underwater systems to address new scientific challenges. ( $) 2007$ Wiley Periodicals, Inc.
\end{abstract}




\title{
Innovation and Operation with Robotized Underwater Systems.
}

\author{
Vincent Rigaud \\ Director of the underwater system Dept Ifremer \\ Zone portuaire de Brégaillon 83507 \\ La Seyne sur Mer France \\ vincent.rigaud@ifremer.fr,
}

This paper reports on the status and design of the operational Remotely Operated Vehicle "Victor 6000 ", rated for $6000 \mathrm{~m}$ depth and of the $3000 \mathrm{~m}$ depth Autonomous Underwater Vehicle "Aster" operated by Ifremer the French Institute for Sea Exploitation.

"Victor 6000" is part of a global system build of subsystems, "scientific modules", winch and cable, dead weight and umbilical, positioning sub-system through acoustic ultra short base line (USBL) techniques, and all the exploitation software for data and dive management. In 2005 the system was equipped with a second toolsled dedicated to high resolution mapping of the sea bed, with both acoustical and optical devices.

"Aster", the first Autonomous Underwater Vehicle (AUV) developed by IFREMER is 4.5 meters in length with a diameter of 0.69 meters. Depending on the payload its weight is between 600 and $800 \mathrm{~kg}$ in air, with a diving depth of 3000 meters. Its cruising speed is between 0.5 to 2.5 meters per second. The AUV is capable of carrying various payloads sections for a wide spectrum of applications. The vehicle can cruise up to a 100km range. For coastal applications this vehicle is operable by a limited crew possibly from a non-specialized vessel.

Both vehicles used for oceanography as well as to continually evolve underwater systems in the achievement of new scientific challenges.

\section{Introduction}

Ifremer has been engaged in the development of underwater technologies since the beginning of the seventies and in the operational use of underwater systems within the European oceanographic fleets. Development of the deep sea ROV Victor 6000, and a complete upgrade of the well-known manned submersible Nautile in 2000-2002, are some of the major activities undertaken recently by Ifremer.

Manned submersibles have been pioneers in the field of operational access to the deep sea for science for twenty years. Along with the Shinkai 6500 from Jamtec in Japan and with the two $M I R$ vehicles from Russsia, Nautile is capable of diving up to a depth of 6000 meters. It was 
overhauled in 2000-2002 and is up to date for science investigation with 1500 operational dives already conducted.

It's mainly dedicated to oceanographic investigation but has also been used for archaeology, for example to dive on the wreck of the Titanic and on oil spill reduction, for example to dive on the wreck of the Prestige off the coast of Galicia. It's a very flexible tool for complex unknown underwater environments .

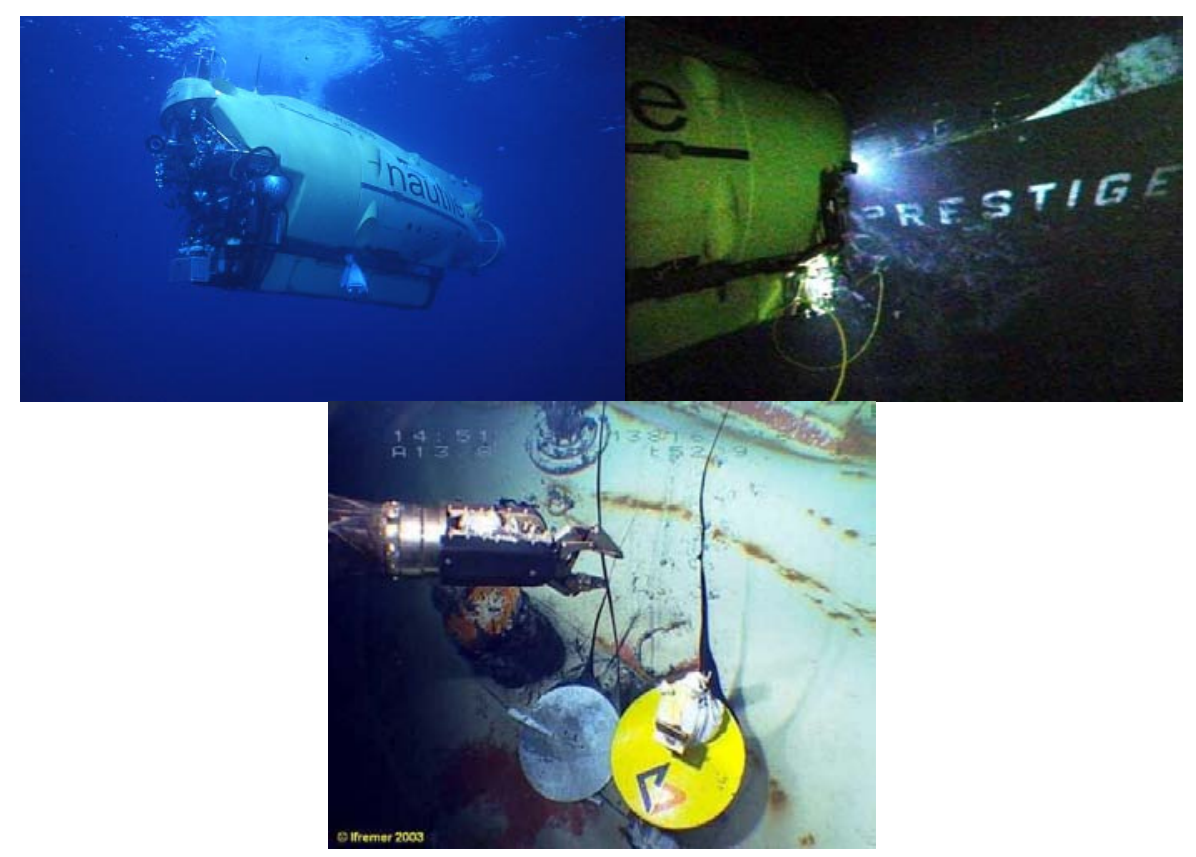

Figure 1- Nautile on the Prestige Wreck:

a-Nautile diving!, b- Nautile filmed by the small associated ROV ROBIN,

c- Stamping an oil leakage

However Nautile is not optimised for surveillance, especially when it is important to optimise the cost of collected data, or when the conditions are not consistent with the use of a heavy deep sea system. Ifremer has been developing a new generation of underwater vehicles with an emphasis on autonomous vehicles.

In the context of deep water technologies, numerous projects have been conducted recently with European partners for offshore applications. This effort started with the development of the supervised AUV Sirene [Rigaud et al, 1999] that was designed for accurate launch and deployment of a benthic station. The prototype was built by Ifremer for depths up to $4000 \mathrm{~m}$ and has demonstrated progress in precise autonomous positioning and tracking using Kalman filter techniques, robust acoustic range-estimators, chirp communication and noise reduction technologies, as well as electro-acoustic-compatibility.

The technology developed in Sirene was applied to the Swimmer research and development project in collaboration with Cybernetix company for the offshore industry [Chardard \& Rigaud, 
1998]. This hybrid AUV, which was based on the Sirene vehicle, carries a classical ROV and was designed to dock on a pre-installed bottom-station linked by a permanent umbilical to the surface. Once docked, the Swimmer "Shuttle AUV" deploys the ROV using the established link with the surface, through the permanent field umbilical. Over and above the spin-off of Sirene technologies, the autonomous docking concept was demonstrated using an innovative, integrated high-precision positioning system (Fig 2).

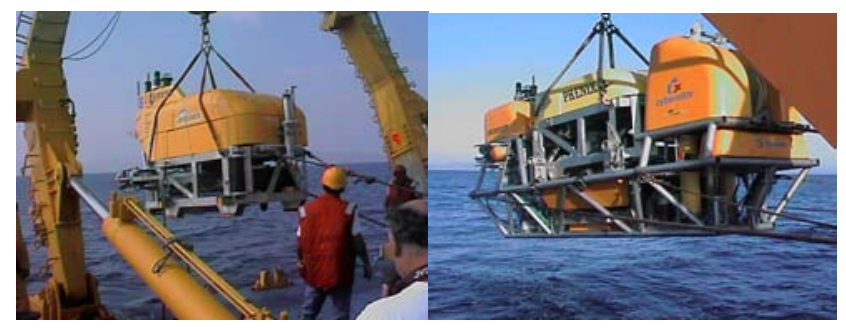

Figure 2: 2-a-Sirene AUV , 2-b-Swimmer Hybrid AUV

The successful development of Swimmer was followed by an ambitious prototype AUV that was built in collaboration with Cybernetix, Hitec-Horten and Herriot Watt University. This is the Alive intervention AUV (Fig 3), fitted for the first time for an AUV, with manipulators. The vehicle is able to dock with grabbers on a typical offshore ROV panel in an acousticallysupervised mode. This project had demonstrated innovative robust optical and acoustical dynamic positioning and sensor based docking, proven at sea in real conditions [Perrier \& Brignone, 2004].

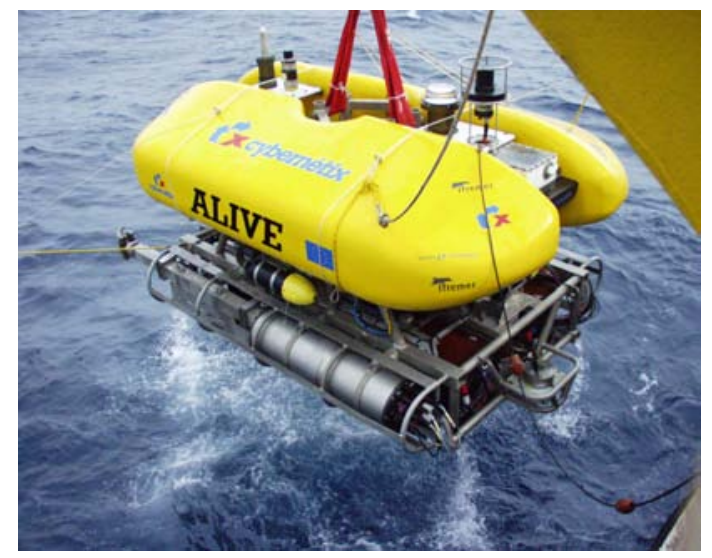

Figure 3: Alive AUV

Beyond these technological advances, the need for a more classical survey AUV has arisen within Ifremer scientific programs, mainly dedicated to environmental survey, in the field of physics, chemical analysis, living resources survey or risk assessments for geophysics ( slope instabilities and seismic surveys). This has led to the set-up and launch of an operational program for a fleet of coastal survey AUVs.

On the ROV "Victor 6000" side, the system has been in operation since 1997 and has been intensively used for multi-science cruise all other the world. The vehicle is in permanent evolution. A new high resolution mapping module has been designed. This scientific tool skid is 
dedicated to "optical and acoustical mapping" at limited altitude for very high resolution "multi modal" mapping.

\section{Victor 6000: maturity and cooperation}

"Victor 6000" the deep sea Remotely Operated Vehicle is rated to reach $6000 \mathrm{~m}$ depth, e.g. $97 \%$ of the ocean depth. The vehicle is part of a global system built of subsystems , "scientific module" (tool sleds), winch and cable, dead weight and umbilical, positioning sub-system through acoustic ultra short base line (USBL) techniques, and all the exploitation software for the data and dive management.
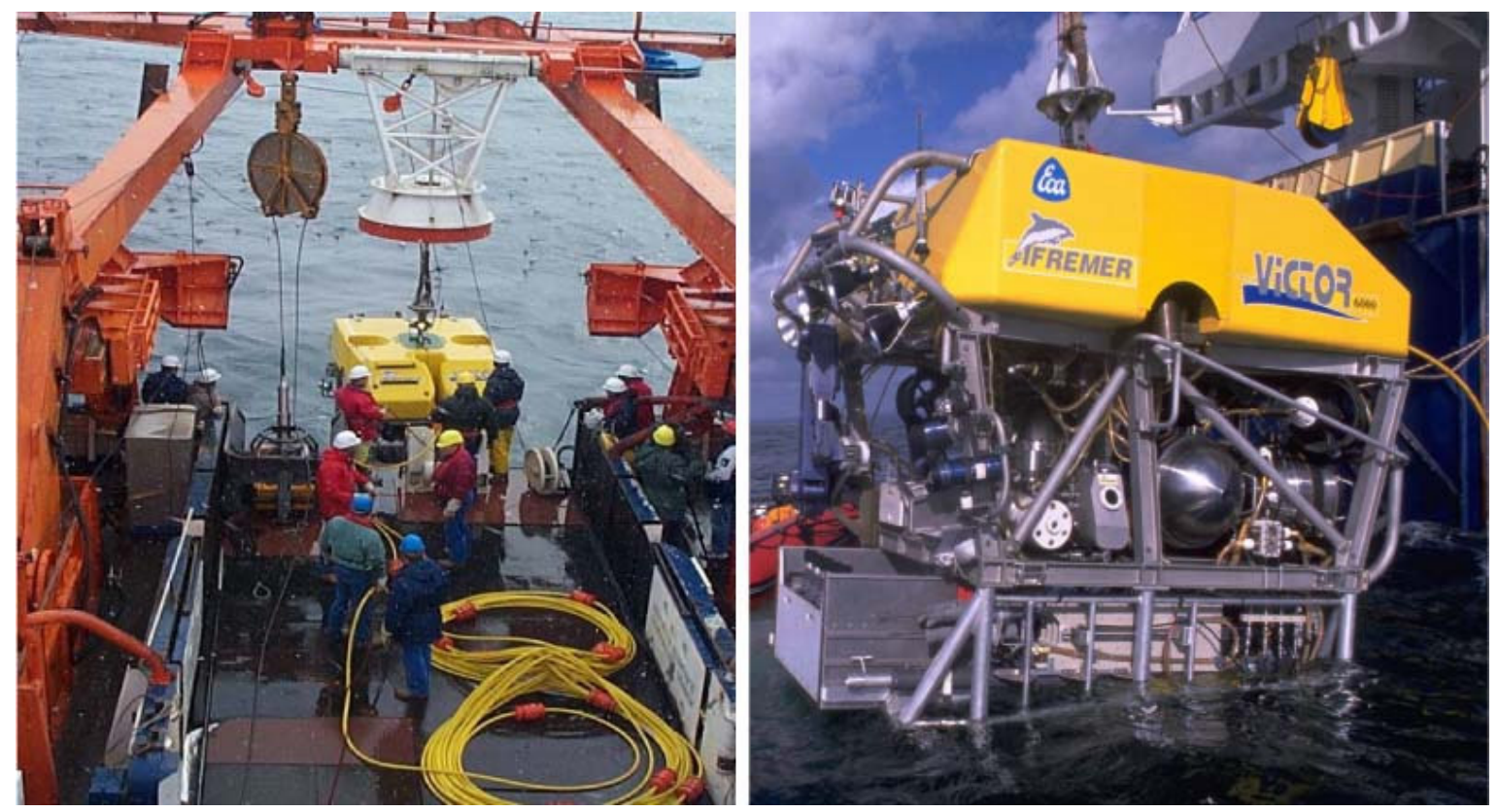

Figure 4 Victor 6000 on R/V Polarstern and on R/V L' Atalante

\subsection{Status and feedbacks}

Since 1997 "Victor 6000" has been fully operational. The statistics of usage are:

- 300 dives since September 1997

- $4200 \mathrm{~h}$ diving, $3500 \mathrm{~h}$ on the bottom

- Mean dive duration $16 \mathrm{~h} 50$

- Mean depth $2021 \mathrm{~m}$

- Max Depth 5917m, Maximum dive duration 101hours

- Around 3 scientific campaigns/year

In 2006 The system was equipped with a second tool skid dedicated to high resolution mapping of the sea bottom, with acoustical and optical devices in cooperation with the Alfred Wegner 
Institute in Germany within a project of a Common Underwater Systems technologies (Virtual) Department (Fig 5).

A deep record dive at high latitude $\left(79^{\circ}\right.$ north) was reached in the Molloy Deep at 5550 meters. The performance obtained up to 2004 during 3500 hours of work/survey (+ 700 hours transiting between sea surface and ocean bottom) near the seafloor have contributed significantly to the observation and the monitoring of the deep benthic ecosystems in various environments of the mid-oceanic ridges and the continental margins.

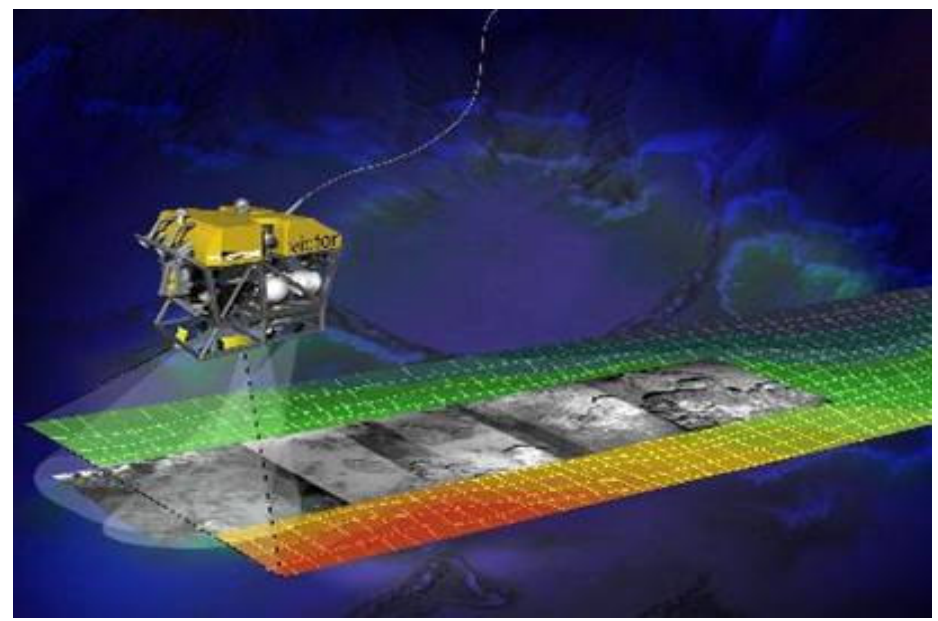

Figure 5. The new High Resolution Mapping Module (See §2.2)

For the video mapping, the ROV "Victor 6000" is equipped with a vertically oriented camera. The Survey of the ocean floor by mosaicking a video stream is carried out at an altitude of about 3 to 5 meters, to ensure a good image quality. As the camera aperture is $60^{\circ}$, the video mosaicking coverage is about the same as the altitude. This means that, in our case, the mosaic width is approximately 3 meters. In addition, geo-referencing is provided on-line by measured or estimated data from navigation including USBL and dead-reckoning. The system has been used and qualified through successive prototyping during several cruises.

\section{Caracole cruise}

The Caracole cruise took place in 2001 on the ship L'Atalante with Victor 6000. It aimed at mapping at a high resolution the carbonated mounds on the continental margin off Ireland. For this purpose, a micro-bathymetry survey was done and was completed by video mosaicking and sampling. Geo-referenced mosaics, built with the MATISSE® software [Petillot et al, 2004],[Borgetto et al, 2004],[Allais et al, 2004] have been produced and embedded into the GIS where high resolution bathymetry survey have been superposed (Fig. 6). The difficulties in optical mapping arising from varying altitude, lighting conditions and navigation accuracy are clearly visible [Borgetto et al, 2004]. 


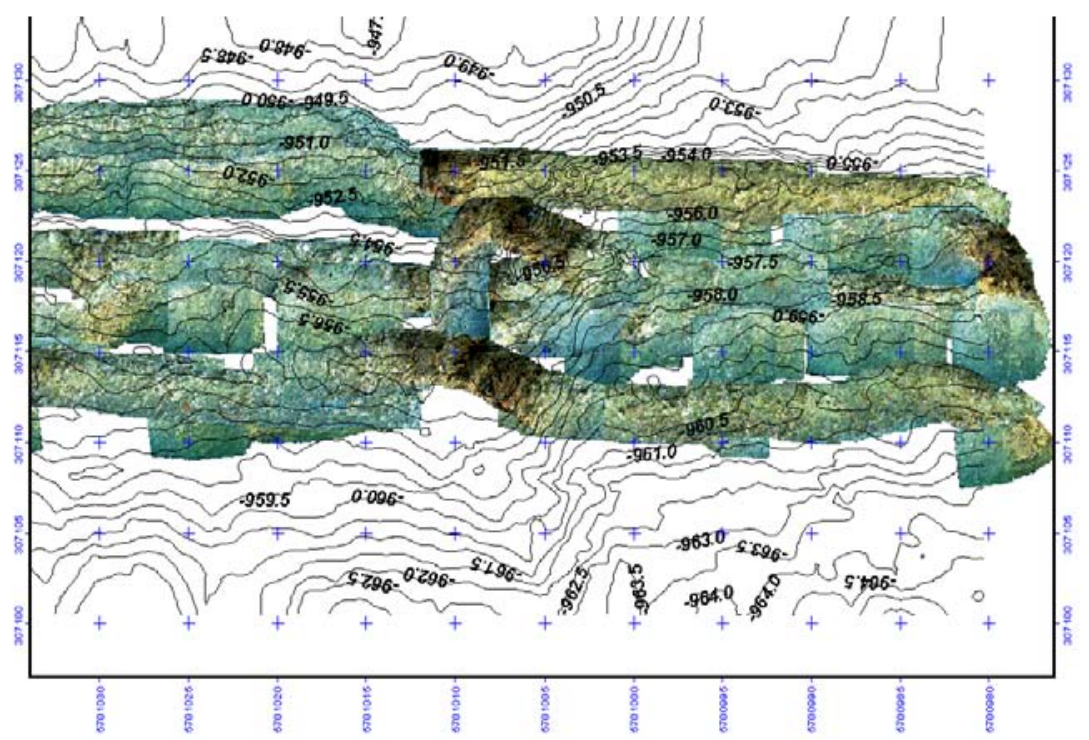

Figure 6- Superposition of Multibeam Numerical Model Of Terrain and optical mosaics $(200 * 50 \mathrm{~m})$

\section{Victor 6000 "in the North" cruise}

This cruise took place during the summer of 2003 in the North Atlantic Sea and the North Sea. Color video mosaicking was especially carried out during the second leg on the Håkon Mosby Mud Volcano (HMMV) in the Northwest of Norway at about 1250 meter depth. It has a diameter of around $1 \mathrm{~km}$ and the purpose was to get an accurate overview of the whole volcano.

During the leg on the mud volcano, seven dives were conducted by Victor 6000. Six of them were partly dedicated to video survey, that enabled the production of about $35 \mathrm{~km}$ of video mosaicking for 50 hours.

The following map (Fig. 7) represents the mosaic prints and shows the full extent of the video mosaicking surveys. The maps were produced in near real time after two dives:

- dive I $44 \mathrm{~h}$ : initial HR survey with Seabat 8125

- dive II 16h : same Survey with EM2000 

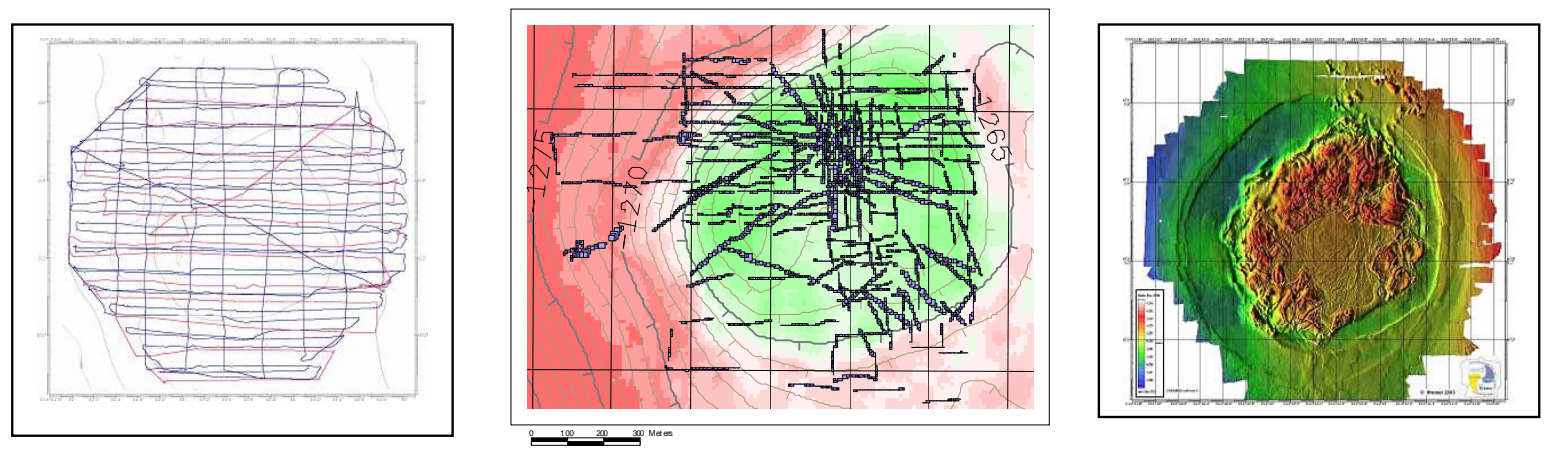

Fig. 7. Tracks of the video mosaics on the Håkon Mosby Mud Volcano.

Left: Hybrid navigation Tracks, Central: In Black lines optical mosaics footprint, right: Multibeam NMT

Complete mapping of the volcano area could not be achieved given the limited coverage of colour video on the seafloor. The objective of the video survey was to produce significant samples distributed over the area in order to stamp areas after segmentation of textured zones.

\section{Marmara-Scarps Cruise: The longest survey.}

The cruise MARMARASCARPS (16 September - 15 October 2002) was devoted to studying the geology and the morphology of submarine scarps in the northern Sea of Marmara. The main aims were to identify historical earthquake ruptures and to attempt a paleoseismological study of the main fault segments. Victor 6000 carried by vessel Atalante was used to acquire a close video and photo imagery, a high-resolution $(0.5 \mathrm{~m})$, high-precision $(10 \mathrm{~cm})$ multibeam bathymetry $(300 \mathrm{~km}$ of near bottom profiles surveyed), to make direct visual observations of the fault breaks and to collect rock samples and 94 shallow cores $(35 \mathrm{~cm} \mathrm{long})$ into the sediment in their immediate vicinity.

\subsection{New Technologies for the High Resolution Mapping Module}

The new high resolution mapping module (HRMM) has been designed to carry on a multibeam 400kHz Reson 7125 sounder, Innovative Led Lights(HMI), vertical colour cameras, a sub bottom profiler, an EK60 monobeam sounder for fluid seeps discovery and all the ad'hoc software including the MATISSE® [Allais et al, 2004] real time video mosaicking system and the CARAIBES® multibeam sounder software.

A new major optical sensor, named OTUS is a Long Range, High dynamic, High sensibility black and white camera. The main sensor is a 1Mpixel CCD cooled by a Pelletier-effect device. Each pixel size is $19 * 19$ um and the camera link is controlled through Ethernet 100 . The main optical characteristics are: 
- Pixel size

: $19 \times 19 \mu \mathrm{m}^{2}$

- Resolution in photo mode

: 1024 x 1024 pixels

- Digitalisation

: 14 bits

- Reading noise

: $<40$ electrons

- Dynamic

$: \geq 80 \mathrm{~dB}$

- Resolution

$: \geq 50 \%$ to 1000 points

- Wtime

: $5 \mathrm{~ms}$ to 1 second

Another innovation has been the use of a $250 \mathrm{~W}$ led light which has been developed for better lightning.
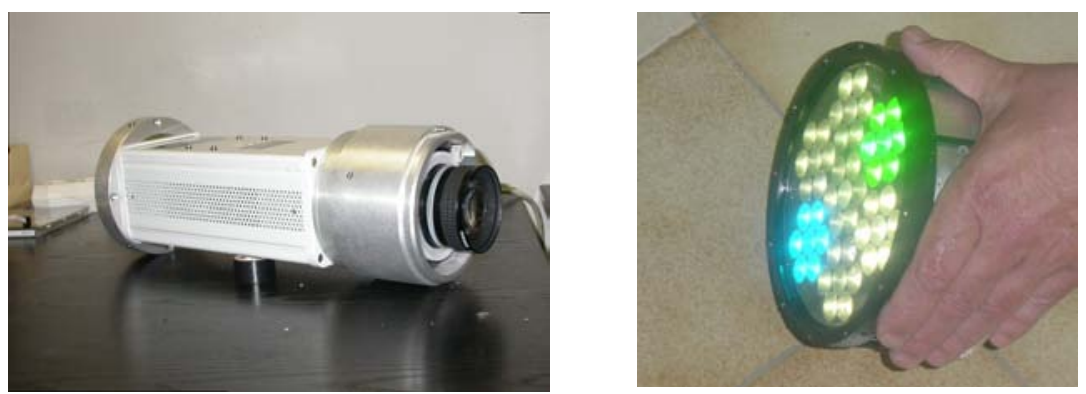

Figure. 8. OTUS camera and with three-colour LED lights.

At $10 \mathrm{~m}$ range from the bottom the size of one picture is $100 \mathrm{~m} 2$, as shown on the following picture.

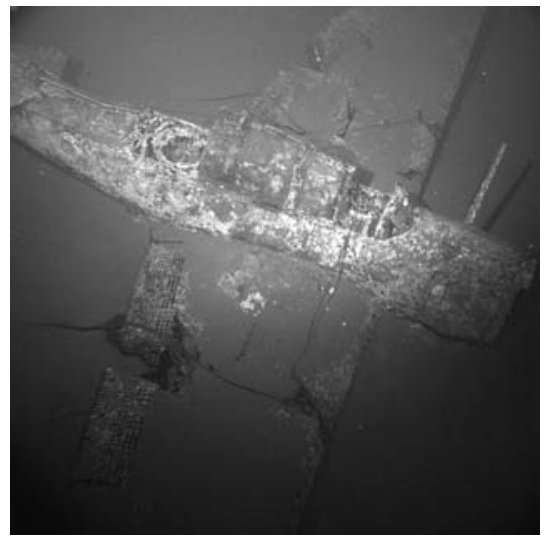

Figure. 9. Image from the OTUS camera covering $100 \mathrm{~m}^{2}$ in one shot.

This image shows a second world war aircraft wreck 
Fig 10 Shown the system configuration for the HRMM, with vertical camera OTUS in the front, with on the left the sub bottom profiler, on the right with red cone the multibeam sonar, flashes in the back and in the middle scientific instrumentations.

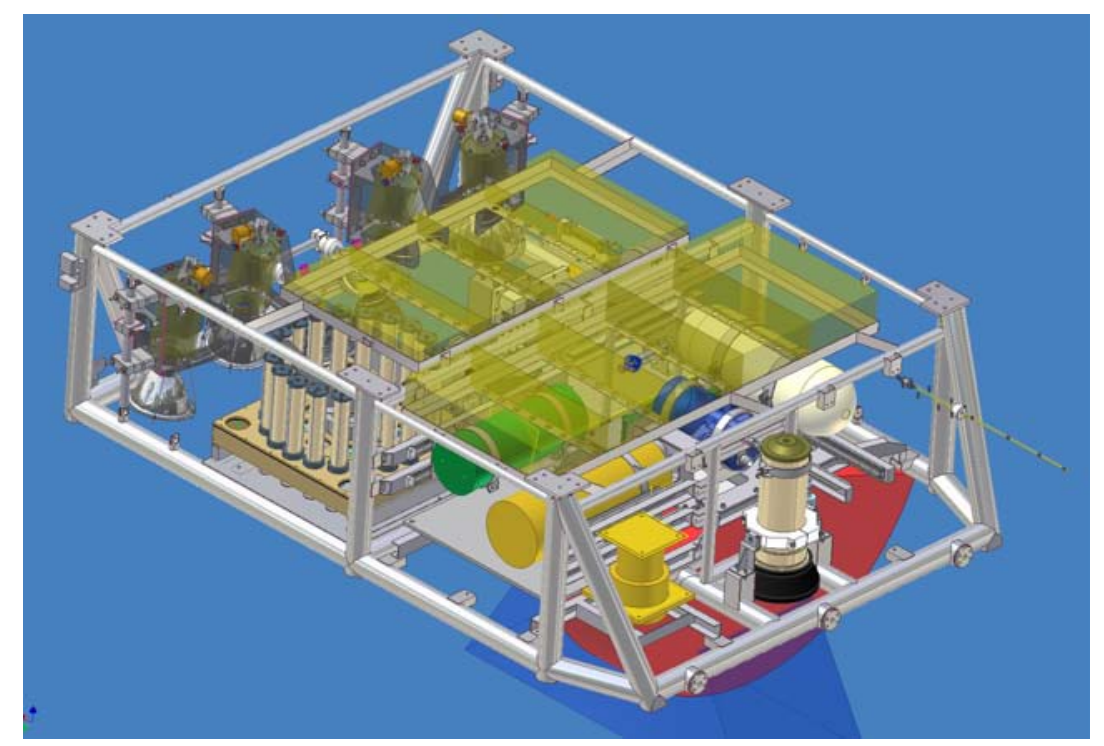

Figure. 10. New High resolution Mapping Module

\section{AUV: ASTER ${ }^{\mathrm{X}}$}

The various fields of physical oceanography, marine geological resources, fish stock evaluation, natural risks assessments; ... in the continental shelf and margin regions, all linked to socioeconomical demands, are fuelling the need for more detailed surveys. Those needs have led Ifremer in 2002 to launch an AUV program with the aim of using autonomous vehicles for operational scientific survey.

The analysis of scientific requirements, collected from several French and European oceanographic institutes, has led to the specification of a 600 to $800 \mathrm{~kg}, 3000 \mathrm{~m}$ depth-rated, modular vehicle with more than $100 \mathrm{~km}$ range capabilities, and around $200 \mathrm{~kg}$ payload capacity. For coastal applications this vehicle would be operated by a limited crew from small $(<30 \mathrm{~m})$ nonspecialised or opportunity vessels.

The final objective of this program is to set-up an operational fleet in order to quickly mobilise a system for environmental survey, for example on non forecasted events (meteorological events, seismic activity, accidental pollution...), but also to be able to use such vehicle on classical cruise in association with ROV.

The first AUV named Aster ${ }^{X}$ is 4.5 meters in length with a diameter of 0.69 meters. Depending on the payload its weight is between 600 and $800 \mathrm{~kg}$ in air, with a diving depth of 3000 meters. Its cruising speed is between 0.5 to 2.5 meters per second. The AUV is capable of carrying 
various payloads in its payload sections for a wide spectrum of applications[Ferguson, 2000][Rigaud et al, 2004].

- Typical classical payloads have been design for :

- Current profiling and physical-chemical parameter measurement

- Sonar imaging for fish-stock evaluation

- Bathymetric sonar, sub-bottom sounder and side-scan sea-bed investigation

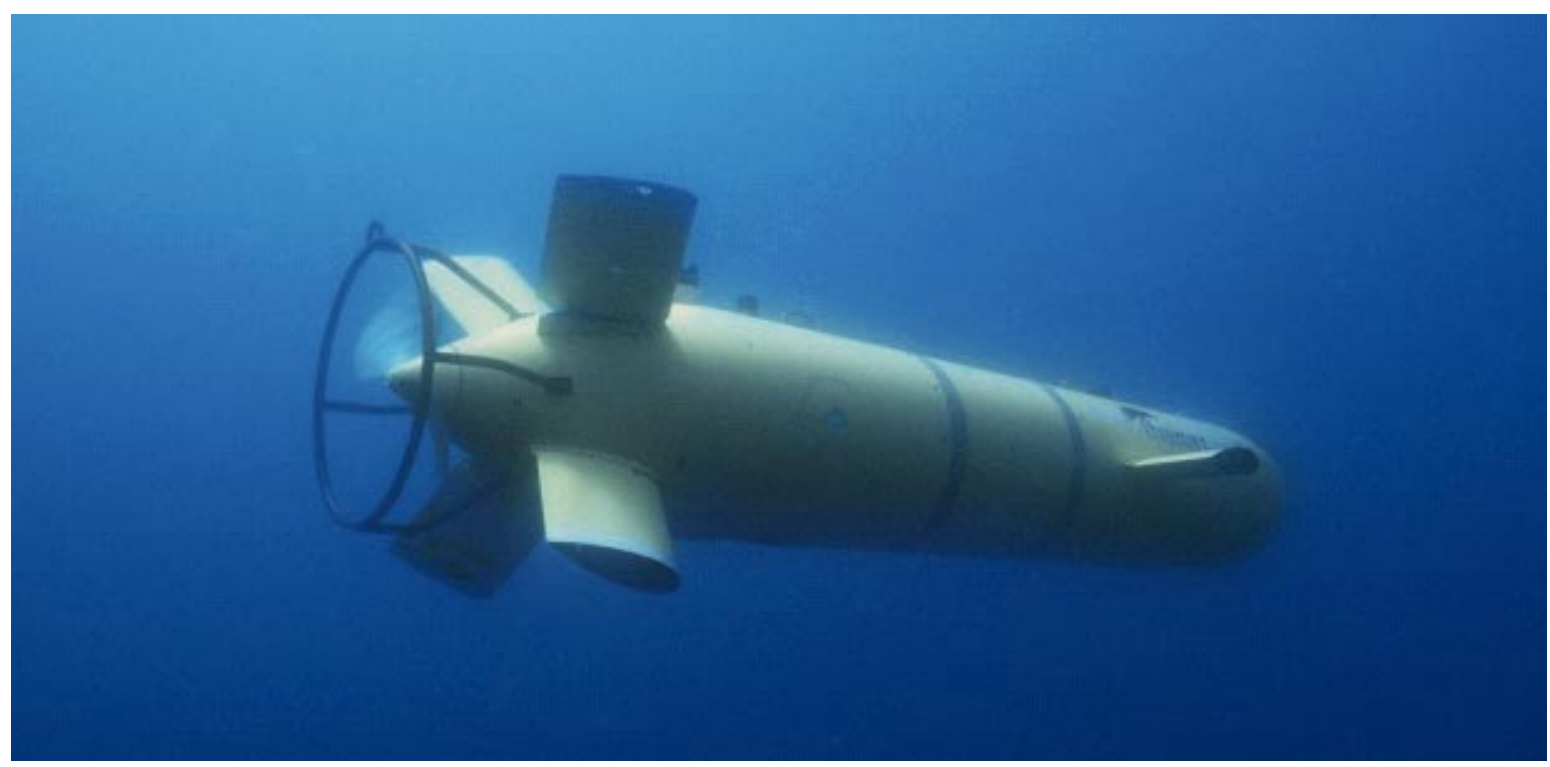

Figure. 11. ASTERX- First Ifremer's Coastal AUV

The following view illustrates the vehicle general arrangement.

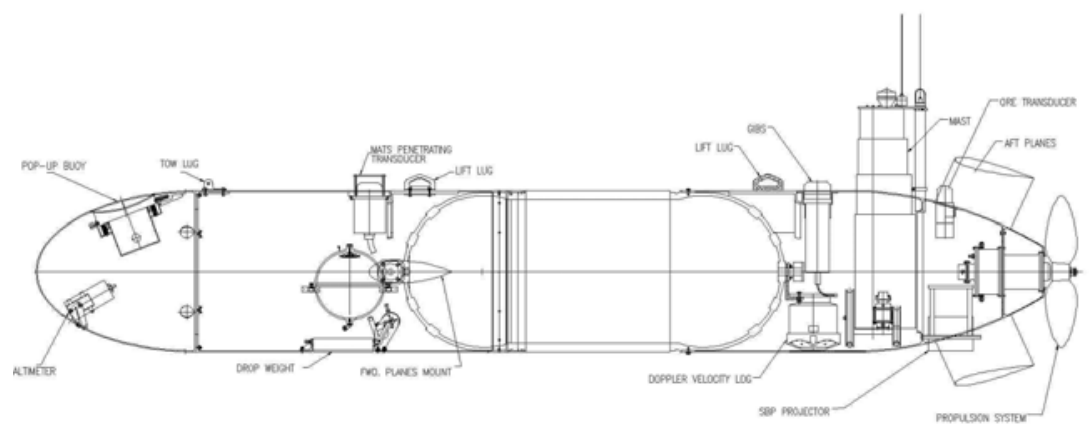

Figure12. General view of the explorer class Aster ${ }^{\mathrm{X}}$ 
The use of such an AUV in coastal areas dictates rules for usage, and an evaluation of operational risks. This has led to select a basic operational scenario, in which the vehicle will surface only if an escort vessel is able to manage the security on the sea-surface. In other cases the vehicle will not be permitted to surface without acoustic contact with the escort vessel and will remain underwater, or ultimately lie on the bottom and wait for the escort vessel to command it to surface. For this reason, sophisticated acoustic communication and relocation functions have been included.

The vehicle made numerous cruises in The Mediterranean sea and in the Atlantic on board Ifremer ships in 2004. Numerous requests to use it on German ships (Missions Planned on the R/V Meteor in 2006 and on the AWI R/V Heincke in 2005, Fig 14-a). Several projects to use it with Spanish team off Barcelona and in the Gulf of Bisquay are already under discussion.

From February 04 to June05 Aster ${ }^{X}$ has been used for 64 Days at sea after several weeks of testing in a pool and in a harbor. Statistics from these tests are: :

- Max depth reached $2500 \mathrm{~m}$

- Max distance in one dive $45 \mathrm{~km}$ with one surfacing

- Mean Operational team 3 people

- Mobilization from 7 different vessels.

For more advanced payloads, the cost and the difficulties remaining in their development are obviously pushing Ifremer to look for cooperation and sharing. This has been done nationally in France where the French CNRS-INSU is bringing support (money and people) to build a shared high resolution acoustic payload (EM2000 Simrad multibeam sonar) with Ifremer. This shared development has already succeeded with a project to build a Scientific Interest Group between CNRS and Ifremer around this topic, for joint research on the surveillance of seismic and slope stability risk off Nice in the Canyon du Var (France).

The Fig 13 shows an underwater high resolution map (EM2000), built and overlaid on another original map built from the ship hull mounted sonar (Simrad EM300). This map is built with the Aster $^{X}$ cruising at 3 knots over the terrain at 60 meters altitude from the bottom in a very rough terrain, from $300 \mathrm{~m}$ depth to 1000 depth. The followed trajectory crossed the lines perpendicularly, climbing with a pitch in order to keep the vehicle axis parallel to the mean slope and descending at constant attitude. Here, the cost of mapping has been optimised, in terms of time of survey ( $18 \mathrm{kms}$ in line $3 \mathrm{~km} 2$ covered in 3 hours, map built on the ship 30 minutes after the end of the dive). This result is an illustration of the data cost optimisation, by minimization of the needed ship time versus the survey time. 


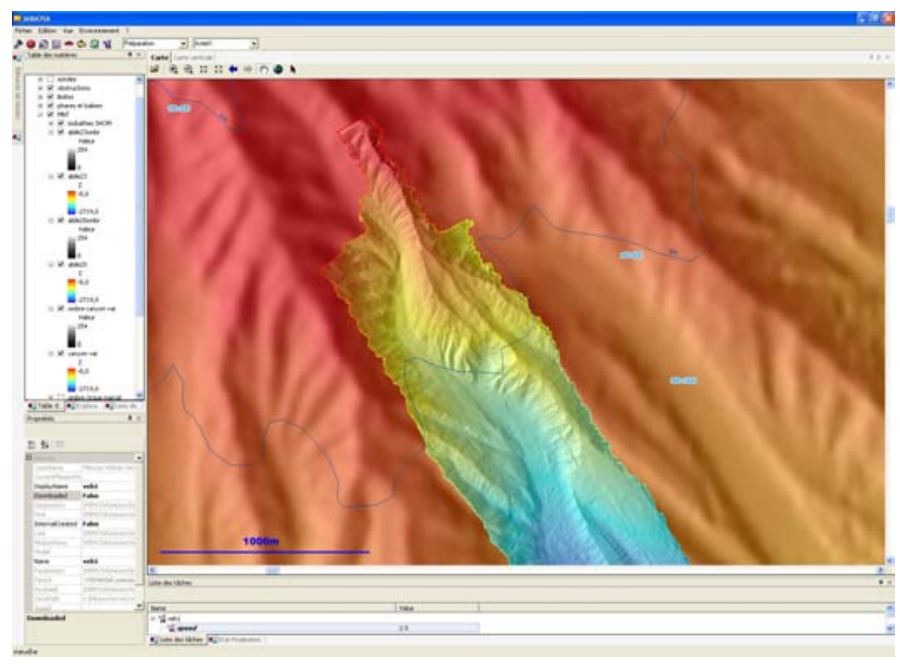

Figure 13: High resolution mapping with MultiBeam sounder, with terrain following function in the Var Canyon from 300 to 1000m depth, crossing the levels lines perpendicularly

More recently a gas detection payload composed of two fishery echo-sounders $(70 \mathrm{kHz}$ and $200 \mathrm{kHz}$ ) was installed during the 2006 "Bionil" cruise off the Nil Fan in the Mediterranean sea, on board the R/V Meteor with German (MPI, Bremen University) and French scientists (Ifremer, CNRS , Fig14-c). Fishery echo-sounders permit to detect gas plumes because it gives the intensity of each echo in the water column under its transducer. As gas has a good acoustic reflectivity, it seems easy to detect plumes near the seafloor (Fig14-b.).

During this cruise the Aster ${ }^{X}$ AUV demonstrated new capabilities. It travelled for $138,880 \mathrm{~m}$ in approximately 41 hours over 6 separate dives, mapping several mud volcanoes and small pop marks with the EM2000 multibeam, indicating gas sweeps activities. It was the first time an AUV fitted with a fishery echo-sounder was used to detect gas. (Fig 14-b. Scientific results of this campaign are not yet published and cannot be referenced or shown in this paper)

A second vehicle was designed and built in 2005-2006. This new vehicle is an optimisation of Aster $^{X}$ with several evolutions to optimised the maintenance costs. Cooperation with AWI in Germany, St Johns university in Canada, and Mississippi University will be active in the next future. 


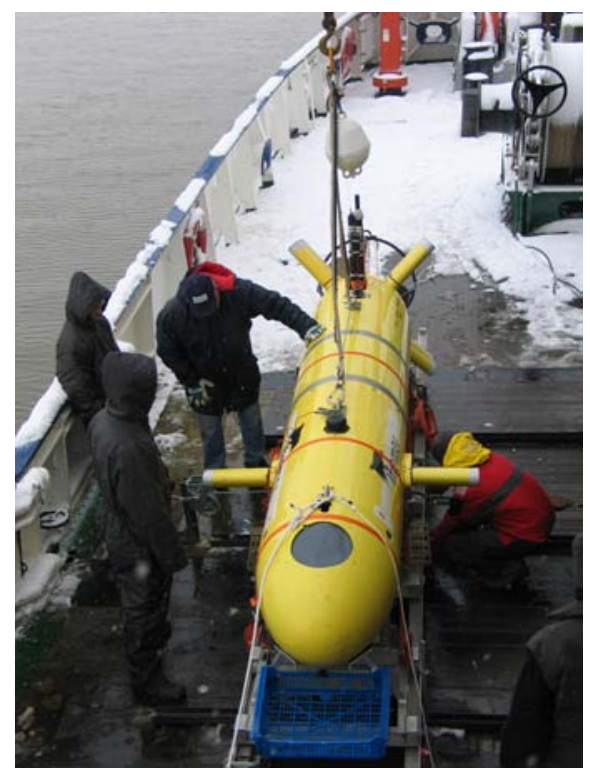

Figure 14-a: Aster ${ }^{X}$ in the North Sea on an AWI vessel

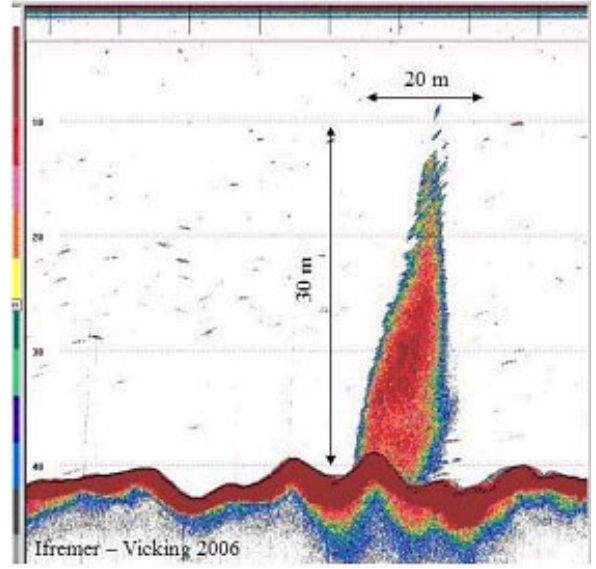

Fig. 14b : Gas detection using EK 60 fishery echosounder - $70 \mathrm{kHz}$ installed onboard ROV Victor6000 during Vicking Cruise of $\mathrm{R} / \mathrm{V}$ Pourquoi Pas in 2006). The altitude of the echosounder above seafloor is $40 \mathrm{~m}$. (Courtesy of Hervé Nouzé, chief Scientist of Vicking Cruise).

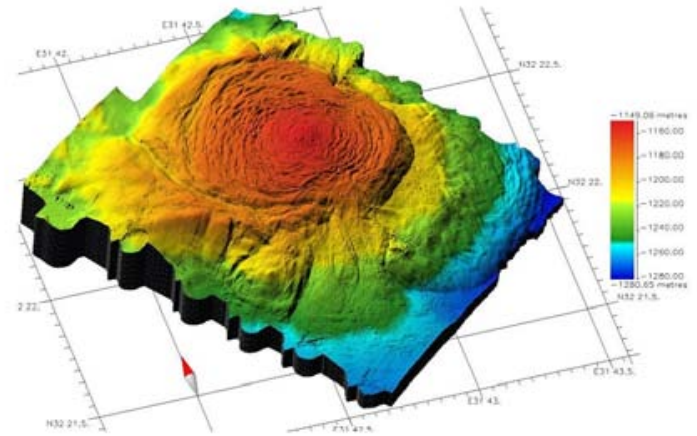

Fig.14c: Ultra-high resolution $(<50 \mathrm{~cm})$ microbathymetry of Amon mud volcano, in the Nile collected using AUV Aster ${ }^{x}$ (see Doc. $\mathrm{N}^{\circ} 2$ ) during the BIONIL Cruise (Chief Scientist Antje Boetius), Mediflux Project, Euromargins Programme. 3D image processed and kindly provided by Georges Buffet, Geosciences Azur. Copyright (c) CNRS-INSU-Géosciences AzurIfremer. 


\section{Conclusions}

With operational AUVs we are still on a learning curve. Developments are permanently underway to reach higher levels of autonomy and behavioural robustness at sea. For example new high level programming mission preparation systems, named Mimosa ${ }^{\circledR}$ and PSE $®$ are being designed for mission building and high level, fault tolerant control. To reach the scientific needs new payload developments are also underway, taking into account the needed instrumental modularity on the system e.g. new Chirp Sediment Sounder, In situ Spectrometer. In addition the scientific requests to use Aster ${ }^{X}$ are very high ( 220 Days at sea requested for 2006), and with the experiences gained during the last 18 months a second coastal AUV has been launched, with several optimisations based on the validated Aster ${ }^{X}$ Concept.

With operational ROV, data fusion of acoustical and optical maps based on concurrent Mapping Localization techniques with data fusion technologies is underway, but is still an open research activity in term of signal processing but also considering the development of new sensors and subsystems. Other research activities based on 3D optical reconstruction with non calibrated stereo are also underway, with a first demonstration of a stereo head installed on the Victor manipulators for a cruise on the Atlantic ridge during the 2006 summer to map hydrothermal vents and cold corals [Sarradin et al, 2004].

In parallel, permanent research and development on heterogeneous systems (AUVs/Ships/autonomous surface systems/underwater observatories), and on autonomy in all the components (energy, positioning, navigation, control), are conducted with regular benchmarking and integration of mature components on operational underwater systems, with a permanent feedback from operation at sea.

\section{References}

Rigaud, V., Semac, D., Drogou, M., Opderbecke, J, Marfia, C.( 1999, May 31 - June 4), From SIRENE to SWIMMER - Supervised Unmanned Vehicles : operational feedback from science to industry. Paper presented at the ISOPE'99 International Conference, Brest, France.

Chardard, Y, Rigaud, V., (1998,October), SWIMMER French group developing production umbilical AUV, Offshore Magazine ,66-67,

Perrier, M., Brignone, L.(May 2004), Optical stabilisation of the ALIVE AUV, Paper presented at the 14th International Offshore and Polar Engineering Conference, ISOPE 2004, vol. 2 pp 233-238, Toulon, France.

Ferguson, J., (May 23rd - 26th, 2000), Explorer - A Modular AUV for Commercial Site Survey, Presented at Underwater Technology 2000 conference, Tokyo, Japan.

Rigaud, V., Michel J.L., Ferguson, J.S., Laframboise, J.M., Crees, T., Leon, P., Opderbecke, J., Chardard, Y., (May 2004), First Steps in Ifremer's Autonomous Underwater Vehicle Program - A 3000m Depth Operational Survey AUV for Environmental Monitoring, Paper presented at . the 14th International Offshore and Polar Engineering Conference, ISOPE, vol. 2 pp 203-208, Toulon, France .

Sarradin, P.M., Sarrazin, J., Cadiou, J.F., Olu, K., Desbruyères, D., Rigaud, V., Drogou, J.F., Lecornu, F., Rolin, J.F., Vuillemin, R., Cambon-Bonavita, M.A., Sauter, E., von Juterzenka, K., 
Boetius, A., Serrão Santos, R., Colaço, A., Pascoal, A., Oliveira, P., Shillito, B., Zal, F., Schultz, A., Taylor, P., Lane, D., Loke, R. E., du Buf, H., Waldmann, C., Cormack, A., Sanfilippo, L., Masson, M., (May 2004), EXtreme ecosystem studies in the deep OCEan :Technological Developments (EXOCET D), Paper presented at the 14th International Offshore and Polar Engineering Conference, ISOPE 2004 International Conference, vol.2 pp 738-745, Toulon, France.

Petillot, Y., Lebart, K., Capus, C., Coiras, E., Lane, D., TenaRuiz, I., Banks, A., Smith, C., Grehan, A., Canals, M., Urgeles, R., Cardew, M., Jaffray, B., Wallace, J., Allais, A.G., Rigaud, V., (May 2004), Improving seafloor data acquisition, integration and visualisation: the AMASON (Advanced MApping with SONar and Video) project, paper presented at Marine Geological Habitat Mapping Conference, GeoHab-2004, Galway, Ireland.

.Borgetto, M., Jauffret, C., Rigaud, V., (May 2004) , Underwater image mosaic correction », paper presented at. the 14th International Offshore and Polar Engineering Conference, ISOPE 2004 conference, vol. 2 pp 427-432, Toulon, France.

Allais, A.G., Borgetto, M., Opderbecke, J., Pessel, N., Rigaud, V., (May 2004) Seabed video mosaicking with MATISSE: a technical overview and cruise results, Paper presented at. the 14th International Offshore and Polar Engineering Conference, ISOPE-2004, vol. 2 pp 417-421, Toulon, France. 